\title{
Nghiên cứu sử dụng xỉ thép làm vật liệu san lấp, đắp nền trong xây dựng
}

\author{
Tạ Văn Luân ${ }^{1 *}$, Lê Thị Song ${ }^{1}$, Phạm Hữu Thiên ${ }^{1}$ \\ ${ }^{1}$ Viện Vật liệu xây dựng, ngõ 235 Nguyễn Trãi, phường Thanh Xuân Trung, quận Thanh Xuân, TP.Hà Nội
}

TỬ KHOÁ

\section{Xỉ thép}

Vật liệu san lấp

Hoạt độ phóng xạ

Thành phần nguy hại

QCVN07:2009/BTNMT

\begin{abstract}
TÓM TẮT
Bài báo trình bày kết quả nghiên cứu sử dụng xỉ thép từ các loại lò luyện thép (lò chuyển BOF, lò hồ quang điện EAF, lò điện cảm ứng IF) ở Việt Nam để làm vật liệu san lấp, đắp nền trong xây dựng. Các mẫu xỉ thép đã được xác định thành phần nguy hại, đặc tính phóng xạ, thành phần hóa, thành phần khoáng và tính chất cơ lý. Kết quả nghiên cứu cho thấy các mẫu xỉ thép không phải là chất thải nguy hại theo quy định trong QCVN 07:2009/BTNMT - Quy chuẩn kỹ thuật quốc gia về ngưỡng chất thải nguy hại. Bên cạnh đó, kết quả tính toán chỉ số hoạt độ phóng xạ an toàn của các mẫu xỉ được thử nghiệm đều đạt yêu cầu làm vật liệu san lấp theo TCXDVN 397:2007 - Hoạt độ phóng xạ tự nhiên của VLXD - Mức an toàn và phương pháp thử. Sau khi gia công xử lý thành phần hạt, tách từ và ổn định thể tích, xỉ thép có thể được sử dụng làm vật liệu san lấp, đắp nền với khối lượng lớn trong xây dựng mà không ảnh hưởng đến môi trường xung quanh khu vực sử dụng.
\end{abstract}

\begin{abstract}
This paper presents results on utilization of steel slags from various steelmaking technologies in Vietnam (including BOF - Basic oxygen furnace, EAF - Electric arc furnace, IF - Electric induction furnace) for application as backfill materials. Steel slag samples were determined the hazardous components, radioactive properties, chemical compositions, mineral compositions, as well as physical and mechanical properties. Research results show that the steel slag samples are not hazardous waste according to QCVN 07:2009/BTNMT-National Technical Regulation on Hazardous Waste Thresholds. In addition, the calculation results of radioactivity index of Vietnamese steel slag meets the requirements for backfill materials according to TCXDVN 397:2007. This research confirms that treated steel slags can be used as a backfill materials without environmental concerns.
\end{abstract}

\section{Giới thiêuu}

Cùng với sự phát triển kinh tế của đất nước, ngành công nghiệp sản xuất gang thép của nước ta đang ngày càng phát triển, cơ bản đã đáp ứng được nhu cầu tiêu thụ trong giai đoạn hiện nay. Theo số liệu khảo sát [1], số lượng lò luyện thép hiện có trong nước gồm : 8 lò chuyển BOF (công suất từ 20 đến 200 tấn) tổng công suất 14,7 triệu tấn thép/năm ; 28 lò hồ quang điện EAF (công suất từ 20 đến 120 tấn) tổng công suất 8,05 triệu tấn thép/năm ; 45 lò điện cảm ứng IF (công suất từ 3 đến 50 tấn) tổng công suất 2,61 triệu tấn thép/năm. Xỉ thép là một sản phẩm phụ của quá trình luyện thép, ước tính lượng xỉ thép phát sinh hàng năm tại nước ta là 2,205 triệu tấn xỉ BOF (chiếm 63,17 \%), 1,208 triệu tấn xỉ EAF (chiếm 34,59 \%), 78,3 nghìn tấn xỉ IF (chiếm 1,24 \%). Mặc dù xỉ thép là một nguồn tài nguyên có tiềm năng cho việc sử dụng làm vật liệu xây dựng nhưng đến nay lượng xỉ thép đang tồn chứa và chưa được xử lý ở nước ta còn khá lớn, gây ảnh hưởng xấu tới môi trường.

Trên thế giới, tại một số quốc gia và khu vực có nền kinh tế phát triển việc nghiên cứu tái sử dụng xỉ thép để làm vật liệu xây dựng trong đường giao thông, làm cốt liệu cho bê tông asphalt, vật liệu san lấp, nguyên liệu cho sản xuất xi măng đã được thực hiện từ lâu. Theo Hiệp hội thép Châu Âu (The European Steel Association) về việc sử dụng xỉ thép ở Châu Âu (bao gồm 22 nước), xỉ thép đã được sử dụng khoảng 12,4 triệu tấn trong năm 2020, trong đó sử dụng làm đường (57 \%), tái sử dụng cho luyện kim và lưu trữ tạm thời (25\%), phụ gia cho xi măng, bê tông (4 \%) [2]. Theo dữ liệu từ U.S.Geological Survey (2021), sản lượng xỉ thép bán ở thị trường trong nước khoảng 7 triệu tấn vào năm 2020 tại Mỹ. Xỉ thép được sử dụng để làm mặt đường asphalt, san lấp và nền đường [3]. Sản lượng thép năm 2020 ở Trung Quốc là 1053 triệu tấn, do đó lượng xỉ thép phát thải là hơn 100 triệu tấn, nhưng chỉ được tái sử dụng khoảng 29,5 \% [4]. Theo dữ liệu của Nippon Slag Association (2016), tổng sản lượng xỉ thép năm 2016 của Nhật Bản đạt 14,1 triệu tấn, tỷ lệ tái sử dụng/tái chế đạt 98,4 \% trong đó các lĩnh vực sử dụng chủ yếu bao gồm : vật liệu san lấp, đắp nền bảo vệ bờ biển, gia cố nền đất, lớp subgrades và lớp enbankments trong đường giao thông [5]. Tại Đài Loan, theo báo cáo của Công ty Tài nguyên CHC tại Hội thảo quốc tế về xỉ thép tại Hà Nội tháng 12/2016 thì tổng lượng xỉ thép phát sinh hàng năm tại Đài Loan là 3,256 triệu tấn/năm, trong đó 
chủ yếu là xỉ BOF, xỉ EAF và xỉ khử lưu luỳnh DeS. Các lĩnh vực tái sử dụng xỉ thép bao gồm : vật liệu cho bê tông asphalt, lớp base trong đường giao thông, xây dựng kỹ thuật dân dụng, cải tạo đất, nguyên liệu cho sản xuất xi măng [6]. Nhìn chung, việc tái sử dụng xỉ thép làm vật liệu san lấp, đắp nền đã được ứng dụng ở nhiều nơi trên thế giới.

Tại Việt Nam, từ năm 2012, xỉ thép đã bắt đầu được sử dụng như là một sản phẩm tái chế thay thế cho đá và được ứng dụng phổ biến ở tỉnh Bà Rịa - Vũng Tàu để làm nền đường, nền móng, thi công mặt bằng tại một số dự án như : nền móng nhà Nhà máy thép Posco SS-Vina, KCN Phú Mỹ I; nền móng công trình dự án Nhà máy sản xuất nhôm Toàn Cầu, KCN Mỹ Xuân B1-Conax; mặt bằng Cảng Posco SS-Vina [7]. Gần đây, từ năm 2017 đến năm 2020, Công ty TNHH gang thép Hưng Nghiệp Formosa Hà Tĩnh đã sử dụng 564.000 tấn xỉ thép làm vật liệu san lấp nội bộ tại một số hạng mục công trình trong khuôn viên nhà máy và chuyển giao cho 7 đơn vị (5 đơn vị ngoài tỉnh Hà Tĩnh và 2 đơn vị tại thị xã Kỳ Anh) sử dụng làm vật liệu xây dựng, phụ gia sản xuất xi măng với tổng khối lượng 1.236.000 tấn [8]. Tuy nhiên các hoạt động tái sử dụng xỉ thép ở Việt Nam vẫn còn nhỏ lẻ, manh mún chưa đáp ứng được nhu cầu xử lý một lượng lớn xỉ thép đã phát thải ra.

Mặc dù trên thế giới đã có nhiều nghiên cứu về tác động môi trường khi sử dụng xỉ thép nhưng tại Việt Nam thì chưa có nghiên cứu nào đánh giá đầy đủ, điều này dẫn đến tâm lý e ngại khi tái sử dụng xỉ thép với khối lượng lớn. Ngoài ra, do quá trình hình thành và làm nguội, xỉ thép thường có kích thước ban đầu khá lớn vì vậy cần phải trải qua quá trình gia công đập, nghiền, sàng, tách từ trước khi đem đi sử dụng. Để cung cấp cái nhìn khái quát về vật liệu xỉ thép, trong khuôn khổ bài báo này, nhóm tác giả trình bày các kết quả đánh giá các thành phần nguy hại, đặc tính phóng xạ, thành phần hóa, thành phần khoáng và các đặc trưng cơ lý của các mẫu xỉ thép để đánh giá khả năng sử dụng các loại xỉ thép trong san lấp, đắp nền.

\section{Vật liệu và phương pháp nghiên cứu}

\subsection{Vật liệu}

Các loại xỉ thép khác nhau được hình thành tùy thuộc vào loại lò được sử dụng trong quá trình luyện thép. Đề tài đã lựa chọn đánh giá 3 mẫu xỉ thép của 3 loại lò đang được sử dụng phổ biến tại Việt Nam là lò chuyển, lò hồ quang điện và lò điện cảm ứng. Ký hiệu mẫu và địa điểm lấy mẫu được cho trong Bảng 1.

Bảng 1. Ký hiệu mẫu và vị trí lấy mẫu xỉ thép.

\begin{tabular}{|c|c|l|}
\hline STT & $\begin{array}{c}\text { Ký hiệu } \\
\text { mẫu }\end{array}$ & \multicolumn{1}{|c|}{ Loại và vị trí lấy mẫu xỉ thép } \\
\hline 1 & BOF & $\begin{array}{l}\text { Xỉ thép lò chuyển, được lấy tại bãi chứa của Công ty } \\
\text { TNHH gang thép Tuyên Quang }\end{array}$ \\
\hline 2 & EAF & $\begin{array}{l}\text { Xỉ thép lò hồ quang điện, được lấy tại bãi chứa của } \\
\text { Công ty TNHH thép Tungho Việt Nam }\end{array}$ \\
\hline 3 & IF & $\begin{array}{l}\text { Xỉ thép lò điện cảm ứng, được lấy tại bãi chứa của } \\
\text { Công ty TNHH MTV thép VAS Nghi Sơn }\end{array}$ \\
\hline
\end{tabular}

\subsection{Phương pháp nghiên cứu}

Nghiên cứu đã sử dụng các phương pháp sau:

\subsubsection{Phương pháp tiêu chuẩn}

- Xác định hàm lượng các chất nguy hại vô cơ theo QCVN 07:2009/BTNMT, Quy chuẩn kỹ thuật quốc gia về ngưỡng chất thải nguy hại

- Xác định mức độ ngâm rỉ và hàm lượng chiết tách kim loại nặng theo JIS A 5015 Iron and steel slag for road construction

- Xác định chỉ số hoạt độ phóng xạ an toàn (I) theo TCXDVN 397:2007 Hoạt độ phóng xạ tự nhiên của vật liệu xây dựng - Mức an toàn trong sử dụng và phương pháp thử

- Xác định thành phần hóa học của xỉ thép theo TCVN 8265:2009 Xỉ hạt lò cao - Phương pháp phân tích hóa học

- Xác định thành phần hạt theo JIS A 5015 Iron and steel slag for road construction

- Xác định khối lượng riêng theo TCVN 7572-4:2006 Cốt liệu cho bê tông và vữa - Phương pháp thử - Phần 4: Xác định khối lượng riêng, khối lượng thể tích và độ hút nước

- Xác định khối lượng thể tích xốp theo TCVN 7572-6:2006 Cốt liệu cho bê tông và vữa - Phương pháp thử - Phần 6: Xác định khối lượng thể tích xốp và độ hổng

- Xác định độ ẩm tối ưu, khối lượng thể tích khô lớn nhất theo 22TCN 333-06 Đầm nén đất, đá dăm trong phòng thí nghiệm

- Xác định chỉ số CBR theo 22TCN 332-06 Xác định chỉ số CBR của đất, đá dăm trong phòng thí nghiệm

- Xác định độ tả thành bột của xỉ thép theo YB/T 801 Steel slag for engineering backfill

- Xác định độ nở khi ngâm của xỉ thép tại các điều kiện nhiệt độ và thời gian bảo dưỡng khác nhau theo JIS A 5015, YB/T 801, EN 1744-1, ASTM D4792

\subsubsection{Phương pháp phi tiêu chuẩn}

- Xác định thành phần khoáng theo phương pháp XRD

\section{Kết quả nghiên cứu}

\section{1. Đánh giá thành phần nguy hại}

Xỉ thép là phế thải công nghiệp của ngành luyện kim, do đó để có thể sử dụng xỉ thép làm vật liệu san lấp, đắp nền thì trước tiên xỉ thép phải được phân định là chất thải không nguy hại theo quy định trong QCVN 07:2009/BTNMT - Quy chuẩn kỹ thuật quốc gia về ngưỡng chất thải nguy hại, đồng thời khi sử dụng làm san lấp, đắp nền cần thỏa mãn các điều kiện về an toàn môi trường khác như khả năng chiết tách hàm lượng kim loại nặng.

Kết quả đánh giá hàm lượng các chất nguy hại vô cơ theo QCVN 07:2009/BTNMT của các mẫu xỉ thép được cho trong Bảng 2 . 
Bảng 2. Hàm lượng các chất nguy hại vô cơ theo QCVN 07:2009/BTNMT.

\begin{tabular}{|c|c|c|c|c|c|}
\hline \multirow{2}{*}{ STT } & \multirow{2}{*}{$\begin{array}{c}\text { Thành } \\
\text { phần } \\
\text { nguy } \\
\text { hại }\end{array}$} & \multicolumn{3}{|c|}{$\begin{array}{l}\text { Hàm lượng tuyệt đối cơ sở, } \\
\mathrm{ppm} / \mathrm{pH}\end{array}$} & \multirow{2}{*}{$\begin{array}{c}\text { Ngưỡng } \\
\text { CTNH, } \\
\mathrm{ppm} / \mathrm{pH}\end{array}$} \\
\hline & & BOF & EAF & IF & \\
\hline 1 & $\mathrm{Sb}$ & 10,418 & $<0,5$ & 1,13 & 20 \\
\hline 2 & As & 4,716 & 3,28 & 1,23 & 40 \\
\hline 3 & $\mathrm{Ba}$ & 4,243 & 9,35 & 19,56 & 2000 \\
\hline 4 & $\mathrm{Ag}$ & 3,476 & $<0,5$ & 0,67 & 100 \\
\hline 5 & $\mathrm{Be}$ & 0,45 & $<0,05$ & 0,11 & 2 \\
\hline 6 & $\mathrm{Cd}$ & $<0,1$ & $<0,5$ & 0,56 & 10 \\
\hline 7 & $\mathrm{~Pb}$ & 292,93 & 11,67 & 2,15 & 300 \\
\hline 8 & Co & 0,36 & 1,46 & 1,92 & 1600 \\
\hline 9 & $\mathrm{Zn}$ & 430,763 & 0,60 & 4,20 & 5000 \\
\hline 10 & Mo & 236,48 & $<0,5$ & 11,15 & 7000 \\
\hline 11 & $\mathrm{Ni}$ & 47,583 & $<0,5$ & 21,61 & 1400 \\
\hline 12 & $\mathrm{Se}$ & $<0,5$ & $<1,0$ & 2,34 & 20 \\
\hline 13 & $\mathrm{Ta}$ & $<5$ & $<1,0$ & 3,32 & 140 \\
\hline 14 & $\mathrm{Hg}$ & 0,282 & $<0,05$ & $<0,05$ & 4 \\
\hline 15 & $\mathrm{Cr}$ (VI) & $<1$ & $<6,0$ & $<0,05$ & 100 \\
\hline 16 & $\mathrm{Va}$ & $<5$ & $<0,5$ & 1,23 & 500 \\
\hline 17 & $\mathrm{~F}^{-}$ & $<0,5$ & $<0,002$ & 62,26 & 3600 \\
\hline 18 & $\begin{array}{c}\text { Tổng } \\
\text { xyanua } \\
\left(\mathrm{CN}^{-}\right)\end{array}$ & $<0,5$ & $<0,1$ & 4,56 & 590 \\
\hline 19 & $\begin{array}{l}\text { Tính } \\
\text { kiềm }\end{array}$ & 12,0 & 10,1 & 9,59 & $2 \div 12,5$ \\
\hline
\end{tabular}

Từ kết quả trên, ta thấy: hàm lượng tuyệt đối của các thành phần nguy hại trong các mẫu xỉ thép $\mathrm{BOF}, \mathrm{EAF}, \mathrm{IF}$ đều nằm dưới ngưỡng theo quy định của QCVN 07:2009/BTNMT. Độ pH của các mẫu xỉ thép cũng đều nằm trong giới hạn từ 2 đến 12,5 theo quy định. Các mẫu xỉ thép này đều không phải là chất thải nguy hại, do đó có thể được xử lý và tái sử dụng cho các mục đích khác nhau, bao gồm cả mục đích làm vật liệu san lấp, đắp nền.

Theo tiêu chuẩn Nhật Bản JIS A 5015 có đưa ra các ngưỡng quy định đối với các kim loại nặng và chất độc hại trong xỉ thép có nguy cơ phát thải ra môi trường trong quá trình sử dụng. Kết quả đánh giá mức độ ngâm rỉ và hàm lượng có thể chiết tách bằng axit đối với các kim loại nặng theo JIS A 5015 của các mẫu xỉ thép được cho trong Bảng 3.

Từ kết quả Bảng 3 , ta thấy: mức độ ngâm rỉ và hàm lượng có thể chiết tách bằng axit của 8 kim loại nặng có trong các mẫu xỉ thép đều thấp hơn mức quy định trong tiêu chuẩn JIS A 5015.

\section{2. Đánh giá đặc tính phóng xạ}

Các vật chất trong tự nhiên đều tồn tại các nguyên tố phóng xạ tự nhiên. Thông thường, các hoạt động của con người làm thay đổi sự phân bố phóng xạ tự nhiên, đồng thời cũng làm thay đổi sự hấp thụ của con người đối với phóng xạ tự nhiên. Phơi nhiễm phóng xạ do vật liệu xây dựng có thể được phân chia thành phơi nhiễm bên trong và phơi nhiễm bên ngoài. Việc tiếp xúc bên ngoài là do bức xạ gamma trực tiếp. Do đó, trước khi sử dụng xỉ thép làm vật liệu san lấp, ngoài việc xác định các thành phần nguy hại có thể tồn tại trong xỉ thép, việc đánh giá khả năng phát tán phóng xạ của xỉ thép là hoàn toàn cần thiết.

Theo TCXDVN 397, đối với vật liệu sử dụng cho mục đích san lấp nền nhà và nền gần nhà thì cần đáp ứng $\mathrm{I}_{1} \leq 1$; đối với vật liệu sử dụng khối lượng lớn trong xây dựng công trình giao thông, thủy lợi ngoài nhà $\mathrm{I}_{2} \leq 1$; vật liệu dùng cho san lấp $\mathrm{I}_{3} \leq 1$. Kết quả đánh giá các chỉ số hoạt độ phóng xạ an toàn của các mẫu xỉ thép được cho trong Bảng 4.

Bảng 3. Mức độ ngâm rỉ và hàm lượng chiết tách của các kim loại nặng theo JIS A 5015.

\begin{tabular}{|c|c|c|c|c|c|c|c|c|c|}
\hline \multirow{2}{*}{ STT } & \multirow{2}{*}{ Chỉ tiêu } & \multicolumn{3}{|c|}{ Mức độ ngâm rỉ / Elution level, mg/L } & \multirow{2}{*}{ JIS A 5015} & \multicolumn{3}{|c|}{$\begin{array}{l}\text { Hàm lượng có thể chiết tách bằng axit/ } \\
\text { Acid extractable content, } \mathrm{mg} / \mathrm{kg}\end{array}$} & \multirow{2}{*}{ JIS A 5015} \\
\hline & & BOF & EAF & IF & & BOF & EAF & IF & \\
\hline 1 & $\mathrm{Cd}$ & $<0,0001$ & $<0,0001$ & 0,0001 & 0,01 & 0,5478 & 0,1750 & 0,3542 & 150 \\
\hline 3 & As & 0,0005 & 0,0008 & 0,0028 & 0,01 & 2,7406 & 0,4747 & 0,5514 & 150 \\
\hline 4 & $\mathrm{Hg}$ & $<0,0001$ & $<0,0001$ & $<0,0001$ & 0,0005 & 1,0276 & 0,1561 & $<0,05$ & 15 \\
\hline 5 & Se & $<0,0001$ & $<0,0001$ & 0,002 & 0,01 & 0,7287 & 0,4327 & 0,7194 & 150 \\
\hline 6 & Bo & 0,0593 & 0,0690 & 0,6321 & 1 & 19,3455 & 40,3414 & 260,67 & 4000 \\
\hline
\end{tabular}


Bảng 4. Các chỉ số hoạt độ phóng xạ an toàn của các mẫu xỉ thép.

\begin{tabular}{|c|c|c|c|c|c|c|}
\hline \multirow{2}{*}{ Tên mẫu } & \multicolumn{3}{|c|}{ Hạt nhân phóng xạ, Bq/kg } & \multicolumn{3}{c|}{ Chỉ số hoạt độ phóng xạ I } \\
\cline { 2 - 7 } & Ra-226 & Th-232 & K-40 & $\mathbf{I}_{\mathbf{1}}$ & $\mathbf{I}_{\mathbf{2}}$ & $\mathbf{I}_{\mathbf{3}}$ \\
\hline BOF & 42,83 & 20,7 & 21,17 & 0,253 & 0,105 & 0,036 \\
\hline EAF & 20,8 & 14,1 & 0 & 0,140 & 0,058 & 0,02 \\
\hline IF & 19,27 & 11,43 & 0 & 0,121 & 0,05 & 0,017 \\
\hline
\end{tabular}

Từ kết quả trên, ta thấy: các mẫu xỉ thép đều đạt yêu cầu về hoạt độ phóng xạ an toàn để sử dụng cho mục đích san lấp, đắp nền trong và ngoài nhà theo quy định của TCXDVN 397.

\section{3. Đánh giá thành phần hóa, khoáng}

Kết quả phân tích thành phần hóa học của các mẫu xỉ thép được cho trong Bảng 5 .

Bảng 5. Thành phần hóa học của các mẫu xỉ thép.

\begin{tabular}{|c|c|c|c|c|c|}
\hline \multirow{2}{*}{ STT } & \multirow{2}{*}{ Chỉ tiêu } & \multirow{2}{*}{ Đơn vị } & \multicolumn{3}{|c|}{ Giá trị } \\
\cline { 4 - 6 } & & & BOF & EAF & IF \\
\hline 1 & $\mathrm{MKN}$ & $\%$ & 3,54 & 2,34 & 1,02 \\
\hline 2 & $\mathrm{SiO}_{2}$ & $\%$ & 19,67 & 24,85 & 67,15 \\
\hline 3 & $\mathrm{Fe}_{2} \mathrm{O}_{3}$ & $\%$ & 36,29 & 40,58 & 12,13 \\
\hline 4 & $\mathrm{Al}_{2} \mathrm{O}_{3}$ & $\%$ & 1,98 & 5,77 & 3,95 \\
\hline 5 & $\mathrm{CaO}$ & $\%$ & 28,52 & 16,05 & 1,72 \\
\hline 6 & $\mathrm{MgO}$ & $\%$ & 2,02 & 3,50 & 5,72 \\
\hline 7 & $\mathrm{SO}_{3}$ & $\%$ & 0,15 & 0,18 & 0,01 \\
\hline 8 & $\mathrm{~K}_{2} \mathrm{O}$ & $\%$ & 0,01 & 0,10 & 0,02 \\
\hline 9 & $\mathrm{Na}_{2} \mathrm{O}$ & $\%$ & 0,05 & 0,62 & 0,21 \\
\hline 10 & $\mathrm{TiO}_{2}$ & $\%$ & 3,04 & 0,79 & 3,68 \\
\hline 11 & $\mathrm{MnO}$ & $\%$ & 3,47 & 3,93 & 2,93 \\
\hline 12 & $\mathrm{P}_{2} \mathrm{O}_{5}$ & $\%$ & 0,22 & 0,13 & 0,02 \\
\hline 13 & $\mathrm{~F}$ & $\%$ & $\mathrm{KPH}$ & 0,002 & 0,001 \\
\hline 14 & $\mathrm{Cl}$ & $\mathrm{ppm}$ & 201,52 & 2,34 & 548,60 \\
\hline 15 & $\mathrm{CaO}_{f}$ & $\%$ & 0,79 & 0,61 & 0,68 \\
\hline
\end{tabular}

Thành phần hóa học của xỉ thép thay đổi tùy thuộc vào loại lò, thành phần liệu nạp và mác thép được sản xuất. Từ kết quả ở bảng trên, ta thấy: xỉ thép BOF và $\mathrm{EAF}$ có thành phần hóa học tương tự nhau, bao gồm các hợp chất chính là $\mathrm{SiO}_{2}, \mathrm{Fe}_{2} \mathrm{O}_{3}, \mathrm{CaO}$. Về thành phần hóa học của xỉ IF có sự khác biệt lớn với hàm lượng $\mathrm{SiO}_{2}$ chiếm chủ đạo lên tới gần $70 \%$. Theo [9] hàm lượng vôi tự do trong xỉ lò chuyển có thể lên tới $12 \%$, tuy nhiên hàm lượng vôi tự do phát hiện được trong mẫu xỉ BOF ở đây khá thấp, có thể là do mẫu xỉ này đã được lão hóa tại bãi chứa một thời gian dài.

Kết quả phân tích bán định lượng thành phần khoáng của các mẫu xỉ thép được cho trong Bảng 6.
Bảng 6. Bán định lượng thành phần khoáng của các mẫu xỉ thép.

\begin{tabular}{|c|c|c|c|c|}
\hline \multirow{2}{*}{ STT } & \multirow{2}{*}{ Tên khoáng } & \multicolumn{3}{|c|}{ Tỷ lệ phần trăm khoáng, \% } \\
\hline & & BOF & EAF & IF \\
\hline 1 & Calcite $\mathrm{CaCO}_{3}$ & - & - & 2 \\
\hline 2 & $\begin{array}{c}\text { Melilite } \\
\mathrm{Ca}_{2}\left(\mathrm{Mg}_{0.5} \mathrm{Al}_{0.5}\right) \\
\left(\mathrm{Si}_{1.5} \mathrm{Al}_{0.5} \mathrm{O}_{7}\right)\end{array}$ & 6 & 18 & 3 \\
\hline 3 & $\begin{array}{c}\text { Merwinite } \\
\mathrm{CaMg}\left(\mathrm{SiO}_{4}\right)_{2}\end{array}$ & 7 & 10 & - \\
\hline 4 & Wustite FeO & - & 15 & - \\
\hline 5 & Cristobalite $\mathrm{SiO}_{2}$ & - & - & 3 \\
\hline 6 & Quartz $\mathrm{SiO}_{2}$ & 11 & - & 32 \\
\hline 7 & Periclase $\mathrm{MgO}$ & - & - & 5 \\
\hline 8 & $\begin{array}{l}\text { Calcium Silicate } \\
\qquad \mathrm{Ca}_{3} \mathrm{Si}_{3} \mathrm{O}_{5}\end{array}$ & 8 & 7 & - \\
\hline 9 & Larnite $\mathrm{Ca}_{2} \mathrm{SiO}_{4}$ & 9 & - & - \\
\hline 10 & Portlandite $\mathrm{Ca}(\mathrm{OH})_{2}$ & 5 & - & - \\
\hline 11 & Albite $\mathrm{Na}\left(\mathrm{AlSi}_{3} \mathrm{O}_{8}\right)$ & 3 & - & - \\
\hline 12 & Hematite $\mathrm{Fe}_{2} \mathrm{O}_{3}$ & - & 4 & - \\
\hline 13 & Magnetite $\mathrm{Fe}_{3} \mathrm{O}_{4}$ & 9 & - & - \\
\hline 14 & Wstite $\mathrm{Fe}_{.916} \mathrm{O}_{4}$ & - & - & 4 \\
\hline 15 & Pha vô định hình & 42 & 46 & 51 \\
\hline
\end{tabular}

Từ kết quả trên, ta thấy: thành phần khoáng của xỉ BOF và $\mathrm{EAF}$ có sự tương đồng nhau với sự xuất hiện của các pha Melilite, Merwinite, Calcium Silicate (tổng tỷ lệ lần lượt là $21 \%$ và $35 \%$ ). Sự khác biệt giữa 2 loại xỉ BOF và $\mathrm{EAF}$ đến từ sự tồn tại của oxit sắt, ở dạng khoáng Magnetite (đối với xỉ BOF), Wustite - Hematite (đối với xỉ EAF).

Kết quả thành phần khoáng của xỉ IF thể hiện khá phù hợp với kết quả phân tích thành phần hóa với sự xuất hiện của khoáng Quartz chiếm tỷ trọng chính.

Pha vô định hình trong tất cả các mẫu xỉ chiếm từ 40 đến $50 \%$.

Giản đồ XRD của các mẫu xỉ được cho trong các Hình 1, 2, 3 .

\section{4. Đánh giá các tính chất cơ lý}

Để đánh giá một số đặc trưng tính chất vật lý và tính chất đầm nén của xỉ thép, các mẫu xỉ thép được gia công cỡ hạt bằng cách đập, nghiền và sàng phân loại, đồng thời với quá trình gia công cỡ hạt là xử lý tách từ tính.

Kết quả xác định một số đặc trưng vật lý của các mẫu xỉ thép sau gia công được cho trong Bảng 7. 


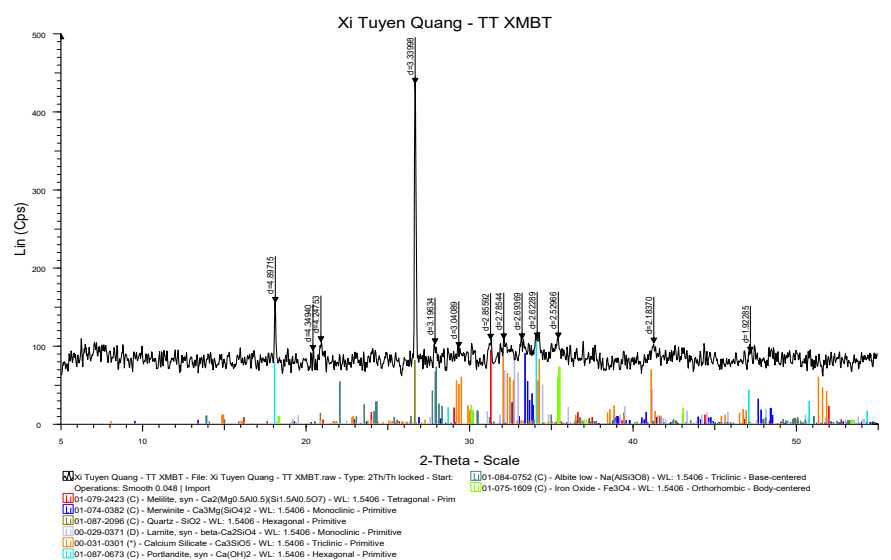

Hình 1. Giản đồ XRD mẫu xỉ BOF.



Hình 2. Giản đồ XRD mẫu xỉ EAF.

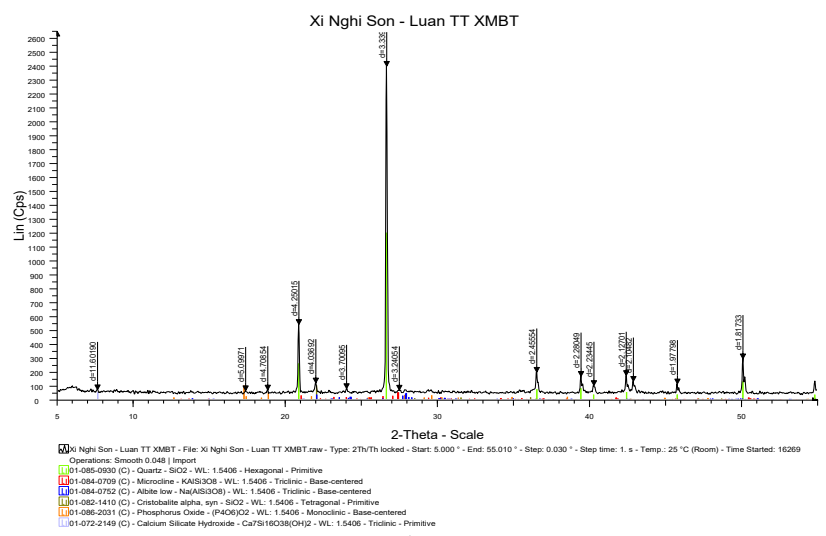

Hình 3. Giản đồ XRD mẫu xỉ IF.

Bảng 7. Các đặc trưng vật lý của xỉ thép.

\begin{tabular}{|c|c|c|c|c|c|}
\hline \multirow{2}{*}{ STT } & \multirow{2}{*}{ Đặc trưng vật lý } & \multirow{2}{*}{ Đơn vị } & \multicolumn{3}{|c|}{ Tên mẫu } \\
\cline { 4 - 6 } & & & BOF & EAF & IF \\
\hline \multirow{2}{*}{1} & $\begin{array}{c}\text { Thành phần hạt, } \\
\text { Lượng lọt sàng tích lũy }\end{array}$ & & & & \\
\hline & $53 \mathrm{~mm}$ & $\%$ & 100 & 100 & 100 \\
\hline & $37,5 \mathrm{~mm}$ & $\%$ & 96,51 & 96,83 & 96,34 \\
\hline & $31,5 \mathrm{~mm}$ & $\%$ & 78,73 & 78,99 & 82,35 \\
\hline & $26,5 \mathrm{~mm}$ & $\%$ & 73,55 & 73,70 & 72,35 \\
\hline & $19,0 \mathrm{~mm}$ & $\%$ & 63,72 & 64,00 & 60,65 \\
\hline & $13,2 \mathrm{~mm}$ & $\%$ & 36,40 & 36,54 & 50,72 \\
\hline & $4,75 \mathrm{~mm}$ & $\%$ & 26,72 & 26,61 & 32,82 \\
\hline & $2,36 \mathrm{~mm}$ & $\%$ & 13,15 & 12,98 & 21,25 \\
\hline & $0,425 \mathrm{~mm}$ & $\%$ & 6,50 & 6,41 & 10,35 \\
\hline & $0,075 \mathrm{~mm}$ & $\%$ & 1,35 & 1,22 & 3,78 \\
\hline 2 & Khối lượng thể tích & $\mathrm{g} / \mathrm{cm}^{3}$ & 3,33 & 3,40 & 3,23 \\
\hline 3 & Khối lượng thể tích xốp & $\mathrm{Kg} / \mathrm{m}^{3}$ & 1900 & 1890 & 1800 \\
\hline
\end{tabular}

Từ kết quả trên, ta thấy: các mẫu xỉ thép có khối lượng thể tích từ 3,2 đến $3,4 \mathrm{~g} / \mathrm{cm}^{3}$ (cao hơn khoảng $25 \%$ so với vật liệu đá dăm thông thường có khối lượng thể tích từ 2,6 đến $2,7 \mathrm{~g} / \mathrm{cm}^{3}$ ). Khối lượng thể tích xốp ở trạng thái tự nhiên của các mẫu xỉ thép (tương ứng với phân bố cỡ hạt như trên) cơ bản là tương đương nhau.

Các đặc trưng tính chất đầm nén của vật liệu xỉ thép được xác định bằng thí nghiệm đầm nén tiêu chuẩn ở trong phòng. Các thông số đặc trưng của nó bao gồm khối lượng thể tích khô lớn nhất $\left(\gamma_{\max }, \mathrm{g} / \mathrm{cm}^{3}\right)$ và độ ẩm tối ưu $\left(\omega_{\mathrm{tu}} \%\right)$ tương ứng. Do $\mathrm{D}_{\mathrm{max}}$ của các mẫu xỉ thép sau gia công lớn hơn 19 mm nên đề tài đã lựa chọn thiết bị đầm chặt Proctor cải tiến - Phương pháp II-D, phù hợp theo 22TCN 333-06. Kết quả xác định các đặc trưng đầm nén của xỉ thép được cho trong Bảng 8.

Bảng 8. Các đặc trưng đầm nén của xỉ thép.

\begin{tabular}{|c|l|c|c|c|c|}
\hline \multirow{2}{*}{ STT } & \multirow{2}{*}{ Đặc trưng đầm nén } & \multirow{2}{*}{ Đơn vị } & \multicolumn{3}{|c|}{ Tên mẫu } \\
\cline { 4 - 6 } & & BOF & EAF & IF \\
\hline 1 & Độ ẩm tối ưu & $\%$ & 9,20 & 7,29 & 6,20 \\
\hline 2 & $\begin{array}{l}\text { Khối lượng thể tích khô } \\
\text { lớn nhất }\end{array}$ & $\mathrm{g} / \mathrm{cm}^{3}$ & 2,40 & 2,295 & 2,100 \\
\hline 3 & Độ ẩm tối ưu hiệu chỉnh & $\%$ & 4,68 & 4,69 & 5,45 \\
\hline 4 & $\begin{array}{l}\text { Khối lượng thể tích khô } \\
\text { lớn nhất hiệu chỉnh }\end{array}$ & $\mathrm{g} / \mathrm{cm}^{3}$ & 2,818 & 2,696 & 2,396 \\
\hline
\end{tabular}

Thí nghiệm CBR được tiến hành để kiểm chứng hiệu quả đầm chặt xỉ thép với phương pháp đầm theo Proctor cải tiến. Kết quả xác định CBR của các mẫu xỉ thép được cho trong Bảng 9. 
Bảng 9. Giá trị CBR của xỉ thép.

\begin{tabular}{|c|c|c|c|c|c|}
\hline \multirow{2}{*}{ STT } & \multirow{2}{*}{$\begin{array}{c}\text { CBR tại các độ } \\
\text { chặt }\end{array}$} & \multirow{2}{*}{$\begin{array}{c}\text { Đơn } \\
\text { vị }\end{array}$} & \multicolumn{3}{|c|}{ Tên mẫu } \\
\cline { 4 - 6 } & & & BOF & EAF & IF \\
\hline 1 & $0,95 \gamma_{\max }$ & $\%$ & 133,0 & 93,0 & 143,0 \\
\hline 2 & $0,98 \gamma_{\max }$ & $\%$ & 171,0 & 103,0 & 162,0 \\
\hline
\end{tabular}

Từ kết quả trên, ta thấy: Giá trị CBR của vật liệu xỉ thép lớn hơn rất nhiều so với vật liệu cát san lấp (cát san lấp có giá trị CBR tại $0,98 \gamma_{\max } \geq 10$ ).

\section{5. Đánh giá độ ổn định của xỉ thép}

Một vấn đề cần lưu ý khi tái sử dụng xỉ thép cho các mục đích xây dựng đó là độ ổn định thể tích. Sự thay đổi thể tích tiềm tàng của xỉ thép là do nó có chứa $\mathrm{CaO}$ và $\mathrm{MgO}$ tự do. $\mathrm{CaO}$ và $\mathrm{MgO}$ tự do thủy hóa dưới ảnh hưởng của độ ẩm dẫn đến sự thay đổi thể tích của khối xỉ thép. Do đó cần phải đánh giá độ ổn định của xỉ thép trước khi sử dụng. Theo quy định của tiêu chuẩn YB/T 801 thì độ ổn định của xỉ thép được đánh giá thông qua 2 chỉ tiêu: độ tả thành bột và độ nở khi ngâm.

\subsection{1. Độ nở khi ngâm}

Đề tài đã tiến hành đánh giá độ nở khi ngâm của xỉ thép tại các điều kiện nhiệt độ và chu trình bảo dưỡng khác nhau theo các tiêu chuẩn hiện hành trên thế giới, chi tiết được cho trong Bảng 10.

Bảng 10. Các điều kiện bảo dưỡng để xác định độ nở khi ngâm của xỉ thép.

\begin{tabular}{|c|c|c|c|c|}
\hline \multirow[b]{2}{*}{ STT } & \multirow[b]{2}{*}{ Điều kiện } & \multicolumn{3}{|c|}{ Tiêu chuẩn áp dụng } \\
\hline & & $\begin{array}{c}\text { YB/T } 801 \\
\text { JIS A } 5015\end{array}$ & $\begin{array}{l}\text { BS EN } \\
13242\end{array}$ & $\begin{array}{l}\text { ASTM } \\
\text { D4792 }\end{array}$ \\
\hline 1 & $\begin{array}{c}\text { Nhiệt độ bảo } \\
\text { dưỡng, }{ }^{\circ} \mathrm{C}\end{array}$ & 80 & 100 & 70 \\
\hline 2 & $\begin{array}{l}\text { Thời gian bảo } \\
\text { dưỡng, ngày }\end{array}$ & 10 & 7 & 7 \\
\hline
\end{tabular}

Kết quả xác định độ nở khi ngâm của các mẫu xỉ thép được cho trong Bảng 11.

Bảng 11. Độ nở khi ngâm của xỉ thép.

\begin{tabular}{|c|c|c|c|c|}
\hline \multirow{2}{*}{ STT } & \multirow{2}{*}{ Tên mẫu } & \multicolumn{3}{|c|}{ Độ nở khi ngâm, \% } \\
\cline { 3 - 5 } & & $\begin{array}{c}\text { YB/T 801 } \\
\text { JIS A 5015 }\end{array}$ & $\begin{array}{l}\text { BS EN } \\
\mathbf{1 3 2 4 2}\end{array}$ & $\begin{array}{c}\text { ASTM } \\
\text { D4792 }\end{array}$ \\
\hline 1 & BOF & 0,96 & 2,82 & 0,73 \\
\hline 2 & EAF & 0,84 & 2,60 & 0,62 \\
\hline 3 & IF & 1,01 & 2,82 & 0,74 \\
\hline
\end{tabular}

Theo quy định của tiêu chuẩn YB/T 801 thì độ nở khi ngâm của vật liệu xỉ thép được dùng trong san lấp kỹ thuật không lớn hơn $2 \%$, từ kết quả ở Bảng 11 ta có thể thấy các mẫu xỉ thép đều đáp ứng được yêu cầu về độ nở khi ngâm theo YB/T 801.

\subsection{2. Độ tả thành bột}

Các mẫu xỉ thép được gia công để lấy cỡ hạt từ 4,75 mm đến $19 \mathrm{~mm}$. Sau đó được hấp trong 3 giờ tại nhiệt độ 93 đến $100{ }^{\circ} \mathrm{C}$. Sau khi làm nguội, các mẫu xỉ thép được sàng loại bỏ các hạt xỉ có kích thước nhỏ hơn 1,18 mm (quy trình thực hiện theo tiêu chuẩn YB/T 801). Kết quả đo độ tả thành bột khi hấp của các mẫu xỉ thép được cho trong Bảng 12.

Bảng 12. Độ tả thành bột của xỉ thép.

\begin{tabular}{|c|c|c|c|c|c|c|c|}
\hline \multicolumn{2}{|c|}{ Tên mẫu } & $\begin{array}{c}\text { Khối } \\
\text { lượng xỉ } \\
\text { thép } \\
\text { trước } \\
\text { khi hấp, } \\
g\end{array}$ & $\begin{array}{c}\text { Khối } \\
\text { lượng xỉ } \\
\text { thép d } \\
>1,18 \\
\text { mm sau } \\
\text { khi hấp, } \\
\mathrm{g}\end{array}$ & $\begin{array}{c}\text { Tỷ lệ } \\
\text { tả } \\
\text { thành } \\
\text { bột, \% }\end{array}$ & $\begin{array}{c}\text { Tỷ lệ tả } \\
\text { thành } \\
\text { bột } \\
\text { trung } \\
\text { bình, \% }\end{array}$ & $\begin{array}{l}\text { Độ lệch } \\
\text { chuẩn }\end{array}$ & $\begin{array}{c}\text { Giới hạn } \\
\text { dao động } \\
\text { trên của } \\
\text { tỷ lệ tả } \\
\text { thành } \\
\text { bột, \% }\end{array}$ \\
\hline \multirow{6}{*}{$\mathrm{BOF}$} & L1 & 1000 & 984 & 1,60 & \multirow{6}{*}{1,067} & \multirow{6}{*}{0,258} & \multirow{6}{*}{1,491} \\
\hline & L2 & 1000 & 989 & 1,10 & & & \\
\hline & L3 & 1000 & 992 & 0,80 & & & \\
\hline & L4 & 1000 & 991 & 0,90 & & & \\
\hline & L5 & 1000 & 989,5 & 1,05 & & & \\
\hline & L6 & 1000 & 990,5 & 0,95 & & & \\
\hline \multirow{6}{*}{$\mathrm{EAF}$} & L1 & 1000 & 995 & 0,50 & \multirow{6}{*}{0,600} & \multirow{6}{*}{0,138} & \multirow{6}{*}{0,827} \\
\hline & L2 & 1000 & 996 & 0,40 & & & \\
\hline & L3 & 1000 & 994 & 0,60 & & & \\
\hline & L4 & 1000 & 992,5 & 0,75 & & & \\
\hline & L5 & 1000 & 994 & 0,60 & & & \\
\hline & L6 & 1000 & 992,5 & 0,75 & & & \\
\hline \multirow{6}{*}{ IF } & L1 & 1000 & 994 & 0,60 & \multirow{6}{*}{0,417} & \multirow{6}{*}{0,137} & \multirow{6}{*}{0,641} \\
\hline & L2 & 1000 & 996 & 0,40 & & & \\
\hline & L3 & 1000 & 997,5 & 0,25 & & & \\
\hline & L4 & 1000 & 997 & 0,30 & & & \\
\hline & L5 & 1000 & 996 & 0,40 & & & \\
\hline & L6 & 1000 & 994,5 & 0,55 & & & \\
\hline
\end{tabular}

Từ kết quả bảng 12 ta có thể thấy giới hạn dao động trên của tỷ lệ tả thành bột của các mẫu xỉ thép $\mathrm{EAF}, \mathrm{BOF}$ và $\mathrm{IF}$ dao động từ 0,6 đến $1,5 \%$, đều nhỏ hơn nhiều so với mức quy định $5 \%$ trong tiêu chuẩn YB/T 801. 


\section{Kết luận}

Từ kết quả nghiên cứu trên cơ sở các số liệu thí nghiệm cho thây: a) Các mẫu xỉ thép trong nghiên cứu đều không phải là chất thải nguy hại theo phân định của QCVN 07:2009/BTNMT. Các chỉ số hoạt độ phóng xạ an toàn của các mẫu xỉ thép đều đạt yêu cầu cho mục đích san lấp, đắp nền trong và ngoài nhà.

b) Khả năng đầm chặt của xỉ thép khá là dễ dàng, chỉ số CBR của vật liệu xỉ thép lớn hơn rất nhiều so với vật liệu cát san lấp thông thường. c) Độ ổn định thể tích của các mẫu xỉ thép đạt yêu cầu theo quy định của tiêu chuẩn YB/T 801 khi sử dụng cho mục đích san lấp kỹ thuật.

\section{Tài liệu tham khảo}

[1]. Nguyễn Thị Hằng, "Nghiên cứu đánh giá thực trạng quản lý, sử dụng xỉ luyện gang, xỉ luyện thép thu được từ quá trình sản xuất gang, thép tại Việt Nam và đề xuất các biện pháp quản lý xỉ luyện gang, xỉ luyện thép", Viện luyện kim đen, mã số ĐTKHCN.226/17, 2017

[2]. The European Steel Association, "European Steel in Figures 2021", Published 17/6/2021, Địa chỉ: https://www.eurofer.eu/publications/brochures-booklets-andfactsheets/european-steel-in-figures-2021/ [Truy cập 25/09/2021]
[3]. U.S.Geological Survey, Mineral Commodity Summaries, "Iron and Steel slag" January 2021, Địa chỉ: https://pubs.usgs.gov/periodicals/mcs2021/mcs2021-iron-steel-slag.pdf [Truy cập 25/09/2021]

[4]. Jianlong Guo, Yanping Bao, Min Wang, "Steel slag in China: Treatment, recycling, and management", Waste Management 78(2018) 318-330

[5]. Nippon Slag Association, "Production and uses of steel slag in Japan" 2016, Địa chỉ: http://www.slg.jp/pdf/Steel\%20Slag\%202016FY.pdf (accessed 3 May 2017) [Truy cập 25/09/2021]

[6]. Milton C.J.King, "Market and Applications of GGBFS and BOF slag in Taiwan", Tuyển tập báo cáo Hội thảo quốc tế "Sử dụng xỉ gang và xỉ thép trong xây dựng vì sự phát triển bền vững”, Hà Nội, tháng 12/2016.

[7]. Lê Việt Hùng, "Dự án Đánh giá chất lượng sản phẩm xỉ thép tái chế và tư vấn thiết lập hệ thống quản lý chất lượng sản phẩm xỉ thép làm vật liệu xây dựng, Phần 2 - Đánh giá chất lượng sản phẩm xỉ thép làm vật liệu san lấp trong xây dựng", Viện Vật liệu xây dựng, 2018

[8]. http://sotnmt.hatinh.gov.vn/sotnmt/portal/read/tin-hoatdong/news/mo-rong-thi-truong-tieu-thu-xi-than-xi-thep-o-khu-kinh-tevung-ang.html [Truy cập ngày 25/09/2021]

[9]. Ivanka Netinger Grubeša, Ivanna Barišić, Aleksandra Fucic and Samitinjay S. Bansode, "Characteristics and uses of steel slag in building construction", Woodhead publishing series in civil and structural engineering: Number 67, 2016. ISBN 978-0-08-100376-3 (online) 